Business Model Innovation and Third-Party Alliance on the Survival of New Firms

\author{
Chander Velu \\ Institute for Manufacturing \\ Department of Engineering \\ University of Cambridge \\ 17 Charles Babbage Road \\ Cambridge CB3 OFS \\ United Kingdom
}

email: c.velu@eng.cam.ac.uk

Tel: +44 (0)1223 765879

Fax: +44 (0)1223 464217 


\title{
Business Model Innovation and Third-Party Alliance on the Survival of New Firms
}

\begin{abstract}
In this study, we address the question of how the degree of business model innovation affects the survival of new firms. We present a newly constructed data set of 129 new firms that launched electronic trading platforms in the US bond market between 1995 and 2004 following the advent of Internet technology. We analyze the founding and survival of these new firms during the period of our study. We find that new firms with a high or low degree of business model innovation are more likely to survive for longer than new firms with a moderate degree of business model innovation. We show that partnering with third-party firms with complementary assets reduces the survival of new firms as the degree of business model innovation increases. We discuss the implications of our findings for managers, policy-makers and researchers.
\end{abstract}

Key words: Business Model Innovation, New Firms, Third-party Alliance, Survival, Financial Services 


\section{Introduction}

Business model innovation is increasingly becoming a priority for managers in terms of creating competitive advantage and achieving superior performance (see Baden-Fuller and Morgan, 2010; Calia, Guerrini and Moura, 2007; Esslinger, 2011). Studies have shown that firms that have grown their operating margins faster than their competitors have placed twice as much emphasis on business model innovation than have underperformers (IBM Global CEO Study, 2008). Business model innovation is particularly important for new firms because it influences their competitive position and, hence, chances of survival (George and Bock, 2011). However, there is a lack of empirical evidence regarding the relationship between business model innovation and the survival of new firms. To address this empirical lacuna, in this paper we examine the relationship between the degree of business model innovation and third-party alliance on the survival of new firms in the US bond markets.

Scholars have emphasized the importance of studying the survival of new firms, as it can influence the incentives for firms to invest in costly and risky attempts to pioneer new markets (Min, Kalwani and Robinson, 2006). Significant work has been undertaken on how incremental and radical innovation affects the survival of new firms; some studies have argued that radical innovation increases the chances of survival of new firms, while others have argued the reverse (see Buddelmeyer, Jensen and Webster, 2010; Sinha and Noble, 2008). However, extant literature has studied the degree of product and process innovation and its impact on the survival of firms, but not business model innovation. Recently, scholars have emphasized the importance of business models for firm performance (Calia, Guerrini and Moura, 2007; Markides, 2006; Patzelt et al., 2008; Zott and Amit, 2008). However, little is known about how business model innovation affects the survival of new firms. 
The business model is a structural template that describes the system of interdependent activities transcending the focal firm and spanning its boundaries in order to create and capture value (Zott and Amit, 2001). In this sense, the business model is the realized strategy of the firm and is a combination of complementary resources that support the commercialization of core products (Vidal and Mitchell, 2013). It follows that business model innovation involves a more systemic change than product or process innovation because it involves changes to the customer value proposition, value creation and value capture (Markides, 2006; Velu and Stiles, 2013). Hence, the degree of business model innovation could have a different effect on firm survival compared to product or process innovation. Moreover, the degree of business model innovation needs to be studied by transcending the firm boundary and examining how partner firms with complementary assets might influence firm survival. Although there is an extensive body of literature on profiting from product and process innovation using complementary assets, the role of business model innovation is relatively unexplored (Teece, 2006).

In order to examine these issues we use contingency theory and profiting from innovation theory to develop hypotheses and to test them empirically. Contingency theory seeks to understand the relationship between certain firm factors and performance (Zott and Amit, 2008). We explore an organizational structural form, the degree of business model innovation as a contingency factor in determining the survival of firms, a crucial form of performance. We then use profiting from innovation theory to develop our understanding of how the degree of business model innovation and partnering with third-party firms with complementary assets jointly impact the survival of firms.

In order to investigate how initial business model innovation affects new firm survival we collected detailed data on every new firm that launched an electronic trading platform in the US bond markets between 1995 and 2004 following the advent of Internet technology. The 
literature on business models is still at a nascent stage and the business model innovation construct is not well operationalized in empirical studies (see Baden-Fuller and Morgan, 2010; George and Bock, 2011). However, to make progress in terms of enhancing our understanding thereof, we must - at least at this initial stage in the evolution of research on the phenomenon - focus on its core elements, even if this means sacrificing some of the richness of the phenomenon (Dasgupta, 2002; Debreu, 1991). In this research, in order to operationalize the degree of business model innovation, we developed a survey to measure the construct at a level that is both abstract and parsimonious enough to permit testable predictions, and yet complex enough to retain the core elements of the phenomenon. In particular, we measured the degree of business model innovation using expert bankers and also collected other detailed data on the platforms to control for factors that might influence survival. To the best of our knowledge this is the first data set of its kind to address the important question of business model innovation and firm survival. We analyze the founding and survival of 129 new firms during the period studied.

The study attempts to make a contribution to the innovation literature by examining the contingent effects of the degree of business model innovation on firm survival and how thirdparty alliance for complementary assets moderates such a relationship. Our first finding is that new firms with a high or low degree of business model innovation are more likely to survive longer than new firms with a moderate degree of business model innovation. Second, we show that partnering with third-party firms with complementary assets reduces the survival of new firms as the degree of business model innovation increases.

\section{Relevant Literature and Hypotheses}

Product innovation implies different customer benefits relative to previous products in the industry (Chandy and Tellis, 1998; Markides, 2006). On the other hand, process innovation 
involves improvement to the production or distribution processes, which reduces the average costs and increases profit margins (Cohen and Klepper, 1996). Business model innovation involves the discovery and adoption of fundamentally different modes of value proposition, value capture and/or value creation to an existing business (Markides, 2006; Teece, 2010). It follows that business model innovations involve systemic changes to the value proposition, value creation and value capture. Despite the importance of business model innovation and the considerable popular interest in such innovation, systematic research on the subject remains sparse. Although much of the literature focuses on the definition of business model innovation, scholars and practitioners increasingly agree on its importance in business strategy (Johnson, Christensen and Kagermann, 2008; Zott, Amit and Massa, 2011). In order to understand better business model innovation, we need to understand the nature of the innovation.

Scholars have emphasized the importance of classifying the nature of innovation appropriately in order to understand its implications (see Linton 2009). Innovations have often been described as either incremental or radical in order to distinguish between refining and improving an existing design and introducing a new concept that departs significantly from past design (see Abernathy and Clark, 1985; Henderson and Clark 1990). Incremental innovation is the introduction of relatively marginal or minor changes to an existing product or process that exploits the potential of an existing design (see Friedman, Roberts and Linton, 2008). Therefore, incremental innovation can be seen as something that is relatively easy for an established firm to implement and which reinforces its dominance, as it requires few modifications to the firm's current routines and processes. On the other hand, radical innovation is based on significant departures from existing design and potentially opens up new applications and markets (see Friedman, Roberts and Linton, 2008). Therefore, radical 
innovation requires significant changes to the organizational routines and processes of established firms.

The impact of the degree of innovation on the survival of firms has been varied. On the one hand, studies have shown that radical innovation reduces the chances of firm survival as a result of the increased level of uncertainty (see Buddelmeyer, Jensen and Webster, 2010; Christensen, 1997; Utterback, 1994). On the other hand, studies have shown that firms that adopt radical innovation are more likely to survive because of higher returns from adoption as a result of gaining a larger market share (see Langerak et al., 2009; Sinha and Noble, 2008; Srinivasan, Lilian and Rangaswamy, 2004). However, extant studies have examined the impact of the degree of product and process innovation, not business model, on firm performance. However, business model innovation involves a more systemic change than product or process innovation. Hence, radical business model innovations can be disruptive when they change the bases of competition by altering the performance metrics by which firms compete (Daneels, 2004).

Several recent studies have found that competitive pressures have pushed business model innovation to the top of the priority lists of CEOs in order to improve performance (IBM Global CEO Study, 2008; GE Global Innovation Barometer, 2013). Scholars have highlighted business model innovation as a vehicle for corporate transformation and renewal (Zott, Amit and Massa, 2011). Demil and Lecocq (2010) explain the use of the business model concept as a tool to address change and innovation through a process of experimentation, refinement and reinvention; Sosna et al. (2010) discuss how trial and error learning can act as a basis for business model innovation; and Johnson et al. (2008) articulate cogently that successful business model transformation follows on from a new understanding and redefinition of the customer value proposition. Studies have also highlighted the need for strategic leadership to overcome barriers caused by the cognitive limitations of senior 
management and asset reconfiguration in order to effect business model innovation for performance improvement (Aspara, Lamberg, Laukia and Tikkaen 2013; Doz and Kosonen, 2010). Bock et al. (2012) add to this line of enquiry by showing the effect of culture and structure on strategic flexibility during business model innovation. In addition, recent studies have highlighted the importance of service based customer value proposition for business model innovation in the context of technology shifts (Tongur and Engwall 2014)), the role of technology transfer organizations (Landry, Amara, Cloutier and Halilem 2013) and embedding cost-effective designs in order to form a commercially viable business concept (Chen, Weng and Yang 2014).

The characteristics of new firms have been shown to affect performance, depending on the type of business model pursued by the firm (Patzelt et al., 2008). For example, in the pharmaceuticals industry, the founding members' experience positively influences the performance of platform firms that focus on the commercialization of research services or enabling technologies, while it negatively influences therapeutics firms that focus on biotherapeutic products (drugs). This is because the therapeutics business model requires the continuous renewal of knowledge compared to platform firms that are able to leverage existing knowledge in different ways. Therefore, in the case of therapeutic firms the founding members' experience and knowledge could prove detrimental to the performance of the firms. Zott and Amit (2008) measured the business model construct by studying 190 entrepreneurial firms listed on the US and European stock exchanges. The authors argue that business model is related to strategy but is a higher order construct that measures realized strategy. The authors focus on novelty (devising new ways of conducting economic exchange) and efficiency (devising new ways to attain transaction efficiency) as design themes for the business model because they are the corresponding themes to product differentiation and cost leadership on the product market strategy level. The study found that 
firms adopting a novelty-centered business model design outperformed firms that had an efficiency-centered design when it was coupled with a differentiation strategy. The study also showed that focusing on one type of business model design (as opposed to multiple business model designs) enhances performance. For example, firms adopting high-efficiency-centered business models were more effective when coupled with lower, novelty-centered business models. However, the extant literature has not examined the impact of the degree of business model innovation on survival.

The body of profiting from innovation literature has argued that in order to appropriate value from innovation, firms need to possess complementary assets to their core proposition (Teece, 1986, 2010). Although there is an extensive body of literature on profiting from product and process innovation using complementary assets, the role of business model innovation is relatively unexplored (Teece, 2006). Exceptions are studies by Desyllas and Sako (2013) and Denicolai, Ramirez and Tidd (2014). Desyllas and Sako (2013) show how intellectual property protection can act as a means of protection for firms to build specialized complementary assets in order to transform the business model. Denicolai, Ramirez and Tidd (2014) show how the novel combinations of external and internal knowledge contribute to sales growth. However, the extant literature does not show how partnering to access complementary assets affects the relationship between the degree of business model innovation and survival.

\subsection{Degree of Business Model Innovation and Survival}

As discussed earlier, the extant literature shows that both radical and incremental product and process innovations could be beneficial but also detrimental to the survival of new firms. We use contingency theory to develop hypotheses on the degree of business model innovation and how it affects performance in terms of firm survival (Min, Kalwani and Robinson, 2006; 
Zott and Amit, 2008). We argue that strategy influences structure via the degree of business model innovation and, hence, is a contingent factor affecting firm performance through survival. In doing so, we argue that the mechanism by which the degree of business model innovation affects firm performance is different from that which affects it as a result of product and process innovation respectively.

Business model innovation is different from product or process innovations as it involves systemic change across the value proposition, value creation and value capture approaches. The business model represents the go-to-market approach of the firm and, hence, the realized strategy (Zott and Amit, 2008). This is different to product innovation, which represents bringing a new product to market, or process innovation, which entails the improved efficiency of particular processes. Committing to a radical change in the business model enables the firm to change the game drastically by creating new markets (Velu and Stiles, 2013). Creating new markets entails new institutions supporting the market and therefore requires complementary resources. The creation of such new markets through radical business model innovation implies avoiding the need to compete in an overcrowded existing market and, hence, to drain the firm's resources. Therefore, we argue that radical business model innovation could increase the firm's survival.

On the other hand, business model innovation involves systemic change and, hence, significant risk. Therefore, incremental business model innovation might imply the opportunity to differentiate the value proposition marginally while reducing exposure to significant external market and technological risks and also reducing internal coordination risks from managing the systemic change. Such an incremental business model innovation enables the market to adjust gradually to the new proposition. We expect less resistance to change from the market and more willing adopters, both of which increase the firm's survival. Moreover, the firm reduces the cost of coordination as a result of designing a new 
interdependent system to effect the incremental business model innovation (Bock et al., 2012). Therefore, in the case of business model innovation we argue that either incremental or radical levels of initial innovation would be best in terms of ensuring the long-term survival of the firm. This is because an incremental or radical business model innovation avoids the pitfalls of intermediate levels of business model innovation whereby the proposition is not sufficiently differentiated from an existing customer value proposition. Furthermore, it does not allow reduction from exposure to significant market or technological risks. As discussed earlier, the business model adopted as a result of business model innovation is the realized strategy of the firm in order to create superior performance. Therefore, a moderate degree of business model innovation has similarities to the 'stuck-inthe-middle' hypothesis of Porter regarding corporate strategy, thus resulting in a poorer performance in terms of survival times. Therefore, we posit the following hypothesis:

Hypothesis 1: The relationship between a firm's survival time and the degree of business model innovation is curvilinear (U-shaped), with maximum failure of firms occurring when an intermediate degree of business model innovation is exhibited.

\subsection{Moderating Effects of Third-Party Partners with Complementary Assets}

The business model is a structural template describing a system of interdependent activities that transcends the focal firm and spans its boundaries in order to create and capture value (Zott and Amit, 2001). In this sense, the business model depicts how a firm chooses to connect the factor and product markets. Therefore, business model innovation is an outwardfacing, highly creative, exploratory process (Johnson et al., 2008).

Business model innovation implies new ways of connecting factor and product markets, which require new knowledge, skills and capabilities as complementary resources. Partnering with third-party firms provides the means to access these complementary resources in order 
to profit from business model innovation (Teece, 2010; Desyllas and Sako, 2013). The complementary assets are typically not available in competitive supply and are subject to unilateral or bilateral dependence (Desyllas and Sako, 2013). During business model innovation, one would expect that reliance on a partner with different skills and operating in complementary markets would help the focal firm to access new knowledge skills and capabilities, thus leading to superior performance and helping the firm to survive longer. However, as the degree of business model innovation increases, relying on partners for appropriability via complementary assets increases the firm's exposure to coordination costs and asset specificity (Bock et al., 2012). Such increases in coordination problems might inhibit the synergies from complementary assets and prevent the benefits of collaboration from being realized (De Luca and Athuahene-Gima, 2007). We expect third-party alliances, which leverage the benefits of complementary assets, to work better when the business model innovation is incremental rather than radical. Therefore, we posit the following hypothesis:

Hypothesis 2: The relationship between a new firm's degree of business model innovation and survival is negatively moderated by partnering with third-party firms with complementary assets.

In order to test the above hypotheses, we collected data on new firm formation and survival in the US bond market and estimated various models, which we describe in the next section.

\section{Data and Methods}

\subsection{Empirical setting}

To test the relationship between business model innovation and new firm survival we study the US bond trading markets between 1995 and 2004. The US bond market is a large securities market with USD 2,650 billion and outstanding as at 2004. In these markets, 
government agencies and corporations issue securities directly in the capital markets, known as the primary market, to raise funds. These securities are normally purchased by institutional investors such as asset-management firms, pension funds and insurance companies. Investors change their portfolio of securities by buying and selling these securities in the secondary market. The bond market is suitable for testing the hypotheses because the advent of the Internet enabled innovation to the existing business model. The bond market displayed the following characteristics between 1995 and 2004:

- An industry in which a traditional business model exists with the potential to be transformed into a new business model with varying degrees of innovation.

- New firms (e-trading platforms) were launched with different degrees of business model innovation.

- Some firms formed third-party alliances to access complementary assets.

- Some of these firms survived while others closed down/exited.

The trading of bonds has traditionally been carried out via dealer banks. Dealers act as intermediaries in matching buyers with sellers and are therefore able to price these instruments. The process of intermediation by dealers was performed almost exclusively via a telephone-based system until the mid-1990s. The advent of the Internet enabled the proliferation of new business models in the bond markets. These business models vary from incremental innovation - whereby the dealers continue to act as intermediaries on the electronic platform - to more radical innovation, which enables direct trading between investors on the electronic platform. The differences between the customer value proposition, value creation and value capture, for the incremental and radical business model innovations respectively, are shown in Table 1.

Table 1 about here. 
The data for this study was collected from various sources. The Bond Market Association (BMA) publishes annual reports with information on various aspects of the bond trading platforms. These BMA reports between 1995 and 2004 provided data on competition, breadth of products, time of launch, geographic coverage, third-party alliances, ownership and description of each platform. The data was supplemented by press releases associated with the launch of each platform, which provided a rich source of data on different attributes of these trading platforms (e.g., type of customer and date of launch). Given the difficulties of obtaining an objective measure for innovation we deemed the use of perceptual measures via expert raters to be an appropriate method (Dess and Robinson, 1984). We describe below the method adopted to obtain the survey measure and other variables of interest.

\subsection{Method}

Dependent variable: The dependent variable is the survival of the new ventures. We examine the exits of the new firms between 1995 and 2010. The electronic trading platform in the bond markets developed following the use of Internet technology as a medium enabling electronic transactions from 1995. The start dates of the new firms were recorded in months from the start date of July 1994 to the actual launch date. The data is right censored at 2010 since we have not observed all potential exits as at that date. The data set consists of 129 new venture firms. We observed 81 exits with the remaining data (48 firms) being right censored. We provide a summary of the variables and data source in Table 2.

\section{Table 2 about here.}

Explanatory variable: We have two main explanatory variables, namely the degree of business model innovation and also third-party alliance partners. We describe below the operationalization of our explanatory and control variables.

Degree of business model innovation: The first explanatory variable of interest is the degree of business model innovation. The literature on business models is still at a nascent stage but 
there is increasing interest among scholars in understanding the importance of business model innovation and its relationship to performance (Fiet and Patel, 2008; George and Bock, 2011; Zott, Amit and Massa, 2011). The construct of business model innovation is still not well operationalized in empirical studies. In this paper, we propose to measure the degree of business model innovation.

Since the degree of business model innovation is not observable, we developed a survey to measure the construct. We measured the degree of business model innovation via a survey administered to a set of expert raters from the bond markets. We framed a survey with short descriptions of the 129 electronic bond-trading platforms. We provided information in terms of the key components of the business model, such as the value proposition, means for value creation and the approach to value capture. In particular, the description provided details such as the customer value proposition, the target customers, the instruments to be traded, the revenue architecture and the operational method of trading. An example of the business model descriptions is provided in Table 3 . We sent this survey to six raters, who were experts in the bond trading market. These expert raters were very experienced across a range of sectors in the bond markets, with an average of over fifteen years of experience. They were asked to provide their level of agreement with the statement, 'This business approach is a business model innovation' $(1=$ strongly disagree and $5=$ strongly agree $)$. To help the expert raters decide on this statement, a short description and an example of a business model innovation were provided as part of the survey.

\section{Table 3 about here.}

In order to account for differences in rating based on familiarity with the platform, we gathered information from the same raters about their degree of familiarity with the business model of each platform. In particular, these experts were asked to provide their level of agreement with the statement, 'I am very familiar with this business/firm' $(1=$ strongly 
disagree and $5=$ strongly agree). We used this information to develop a weighted average rating of the degree of business model innovation for each platform. Hence, if an expert-rater were very familiar with the platform, his/her score on degree of business model innovation would be given a relatively higher weight than the corresponding innovation rating given by an expert who was less familiar with the platform. The innovation rating thus obtained was rounded up to the nearest integer. Therefore, we have an explanatory variable, which takes integer values of between 1 and 5, and provides a measure for the degree of business model innovation. Moreover, in order to test whether there was any bias due to familiarity of the more recent trading platforms, we correlated the familiarity reported by each respondent with the time of launch of the platforms. We did not find any statistically significant correlations, which imply that we can be reasonably confident that there was no bias due to familiarity of the more recent trading platforms.

As noted earlier, the expert raters provided scores that rated a platform to be more innovative when there were systemic changes across the customer value proposition, value creation and value capture. For example, BondBook, which allowed direct trading among investors, was rated higher in terms of degree of business model innovation when compared to MarketAxess, which marginally altered the existing trading practice on the telephone and migrated it to an electronic interface, whereby investors still traded via a dealer bank. Based on the expert ratings, BondBook could be considered a radical business model innovation compared to the more incremental nature of business model innovation of MarketAxess. This difference is illustrated in Table 1.

In order to test the validity of this variable we checked its compatibility with an independently collected measure of innovation by The Banker magazine (Piggot, 2001). The Banker provided an independent rating of a sub-sample of platforms with respect to the 'design' aspect of the platforms. The 'design' aspect of the platform is a good proxy for 
business model innovation, as the survey in The Banker aims to examine the level of difference of the business approach of the new platforms, including various aspects of the customer value proposition. The rating was carried out via a survey of 40 institutions on individual electronic trading platforms. This data provided a proxy for the degree of business model innovation. We conducted a Wilcoxon test between our construct for the degree of business model innovation and the score given by the independent study in The Banker (Piggot, 2001). The Wilcoxon test showed a significant pair-wise matching $(\mathrm{p}<.01)$, which provides confidence that our survey rating is a reliable proxy for the degree of business model innovation construct. The Wilcoxon test is a parametric test. However, in order to test for the robustness, we also did the comparison using the non-parametric Fisher-Pitman test, and the results were consistent with the Wilcoxon text whereby it revealed significant pairwise matching $(\mathrm{p}<0.01)$. Therefore, our measure of the degree of business model innovation is compatible with the independent measure as reported in The Banker magazine (Pigott, 2001).

In order to verify the inter-rater reliability, we conducted the Proportional Reduction in Loss (PRL) reliability measure analysis (Rust and Cooil, 1994) on our ratings of six experts. The proportion of inter-judge agreement corresponded to 85 per cent, which is above the acceptable level of agreement between judges on their ratings of the business model innovation (Nunnally, 1978). In addition, we conducted Wilcoxon tests between the ratings of different experts, where we found significant evidence for inter-rater score reliability $(\mathrm{p}<.05)$. Both these tests provide confidence that the expert raters are in agreement with one another in their ratings of the platforms.

Third-party alliance partners: The second explanatory variable of interest is whether there was a third-party alliance formed to benefit from complementary assets. We examined the BMA reports and press releases to determine whether the trading platform formed an alliance 
with any third-party firm in order to have synergies from complementary assets. For example, an alliance with Bloomberg (a major established firm that distributes information in the financial services industry) would enable the new platform firm to benefit from the large distribution network of Bloomberg. When an alliance was formed with a third-party firm in order to benefit from complementary assets we coded this variable as 1 and 0 otherwise.

Control variables: We included several control variables in our research model to enable a more accurate test of our hypothesis. Prior research has shown that the performance of firms depends on factors such as ownership (Colombo and Delmastro, 2001), degree of competition in the market place (Schmidt, 1997), diversification strategy of the firm (Colombo and Delmastro, 2001), geographic location (Chung and Kalnis, 2001) and size (Klepper, 1996).

The type of ownership matters because of the ability of the owners to redeploy resources and the commitment to recover sunk costs (Dunne et al., 1989). We control for ownership by including a construct to measure the presence of entrepreneurs as ownermanagers. The degree of competition can influence the survival of firms as a result of additional managerial effort to reduce failure (Schmidt, 1997). We control for competition by measuring the degree of product market competition across the different securities. The level of diversification strategy of the firm matters because of the ability of firms to cross-subsidize between different product lines (Colombo and Delmastro, 2001). We control for the level of diversification strategy using a measure that captures the breadth of the products that the firms provide to the market. The geographic location of the firm matters because firms locating in a similar geography could result in a spillover of knowledge and therefore agglomeration effects (Chung and Kalnis, 2001). We control for geographic effects using a measure that captures whether the firm is locating across more than one geography. Finally, size is important because arguably larger firms might have more resources to withstand lower performance than smaller firms (Klepper, 1996). Since we are unable to measure directly the 
size of the firms in our sample as a result of unavailability of data, we provide a proxy measure to capture size. In particular, we control for whether an incumbent firm had an equity stake in the new firm. The new firm with the investment support of an incumbent firm is more likely to have more resources when compared to not having such backing, and hence this acts as a proxy for size. We next describe the operationalization of our control variables. Entrepreneurs as owner-managers: The press releases associated with the launch of the platforms provided information about whether existing employees of the banks, major financial and non-financial firms left their jobs to set up these platforms. We cross-checked in order to validate that these employees were owners and also held senior management positions within the new trading-platforms. We call these employees entrepreneurs as ownermanagers. We created a dummy variable to account for the presence of entrepreneurs as owner-managers in the new trading platform. If an entrepreneur were present as an ownermanager in the platform, this dummy variable would be set to 1 and 0 otherwise.

Competition: The traditional method of measuring competition in the literature is to use market-share concentration (see Aghion et al., 2005). However, since we are examining nascent industries with start-up firms, the market share concentration is not available. Therefore, we proxy the market-share concentration via an index. In particular, we developed an index to operationalize the product market competition faced by the platforms at the time of their launch. Although we were studying one industry we were able to analyze the competition by examining the degree of competition in the different product categories within the overall industry.

The BMA reports defined 11 products or financial instruments (e.g., Treasury bonds, Asset Backed Securities (ABS), Mortgage Backed Securities (MBS), among others) that each of these trading platforms used to enable trading between customers. The ratio of the number of platforms trading in a particular instrument category with respect to the overall number of 
platforms existing at the time of launch of a platform provided a measure of the degree of competition in these markets. We call this ratio $c_{i t}=\frac{n_{i t}}{N_{i t}}$, where $n_{i t}$ is the number of platforms trading in instrument $i$ at time $t$, and $N_{i t}$ is the overall number of platforms existing at time $t$. The measure of the degree of competition is calculated as the average value of the ratio for all the instruments that the platform traded in, $C_{p t}=\frac{\sum_{i=1}^{k} n_{i t}}{k}$, where $p$ is the platform's name, and $k$ is the number of instruments traded by that platform. For example, let us assume that platform A (launched in 1997) traded in two instruments (e.g., Treasury bonds and $\mathrm{ABS}$ ). In addition, for illustrative purposes, we assume the ratio of the number of platforms trading in each of these instruments in 1997, where $c_{\text {Treasury }, 1997}=0.23$ and $c_{A B S, 1997}=0.27$. Then the competition index for platform $\mathrm{A}$ is $C_{A, 1997}=\frac{0.23+0.27}{2}=0.25$. This construct operationalizes product market competition, whereby the higher the number of trading platforms already operating in a particular instrument category, the higher the product market competition in that market. The data on the number of platforms existing in each instrument category was obtained from the BMA reports.

Breadth of the platform: We measure the breadth of the platform by the number of products offered by the platform. The BMA reports categorized the number of instruments traded by each platform into 11 general categories, as discussed earlier. The breadth measure is a count variable indicating the number of instruments that were enabled to trade on each of the platforms respectively.

Geographic spread: We operationalized the geographic spread of the platform by examining whether the platform traded just in its own domestic market or in both its domestic and international markets. The bond platforms were domiciled either in Europe or the US. As a result of the international nature of bond markets, we classified domicile as either US or Europe. Therefore, when the platform traded in both its domestic market and an international 
market (e.g., the US and Europe) the variable was given a value of 1. If the platform traded only in the domestic market (either the US or Europe) then the variable was coded as 0 . We obtained the data for this variable from the BMA reports.

Size: We operationalized the size of the firm by using a proxy as to whether the incumbent firm in the industry took an equity stake in the platform. When an incumbent investment bank had an equity stake in the platform the variable was given a value of 1 and 0 otherwise. The data for this variable was obtained from the BMA reports and press releases.

In Table 4 we present the descriptive statistics and the correlation matrix for the variables of interest. All the correlations are below 0.3 and do not pose any significant issues.

\section{Table 4 about here.}

\section{Econometric Model and Regressions}

We are interested in estimating the probability of the new firms exiting when they reach a certain age. We do not have information on the length of survival for firms that continued to survive at the end of our period of analysis. Therefore, we have right censoring of our data. We use a proportional hazard model to assess survival of the firms. Conventional statistical methods such as Ordinary Least Squares (OLS) for estimation are ruled out because of the violation of least squares assumptions and because they do not correct for the problem of right censoring. The following model describes a proportional hazard model, which can be formally represented by:

$$
h\left(t / x_{i}\right)=\exp \left(\beta_{0}+\beta_{i} x_{i}\right) \text { for } t=1 \ldots . . k,
$$

where the left-hand-side variable is the hazard rate (i.e., the probability that the firm exits at time $t$ given that it survived until $t$-1). The parameters $\beta_{0}$ identify the baseline hazard function, which provides the exit rates for a firm whose covariates denoted by the vector $x$ assume a value of 0 and $\beta_{i}$ is the vector of regression coefficients. We use the exponential distribution, which assumes that the hazard rate for survival remains constant throughout the 
period of study. We also test for robustness of our results with a Weibull distribution whereby the hazard rate monotonically increases or decreases, which is estimated from the data. We clustered the analysis by the cohorts of the launch times of the firms.

Since we are using a proportional hazard model to assess the survival of the firm, we need an assessment to ensure that the proportional hazard assumption is met (Hosmer and Lemeshow 1999). The proportional hazard model assumes that the proportionate increase or decrease in risk associated with a set of characteristics relative to the baseline case is the same for all time durations, $t$. If the relationships between the independent variables and the dependent variable are also a function of time then the proportional hazard assumption is violated, making the model unsuitable for the study. Two generally accepted testing strategies are available for the proportional hazard assumption (Hosmer and Lemeshow, 1999). The first test is to conduct a time-dependent proportional hazard regression with the independent variables and the natural logarithm of time. The second test is the examination of Schoenfeld residual plots. We conducted both tests for our study.

In the first test we ran the proportional hazard model by including both main effects (degree of business model innovation and third-party alliance) and an interaction term between the construct to be tested and the natural logarithm of time. The Wald test, which tests the significance of the natural logarithm of time term, was found to be non-significant, providing evidence that the proportional hazard assumption was met for the degree of business model innovation and third-party alliance with respect to the dependent variable. In the second test we plotted the Schoenfeld residuals for both the variables of interest (degree of business model innovation and third-party alliance) against the natural logarithm of time. Visual inspection indicates that the residuals were fairly random and neither trended in a particular direction nor showed any form of clustering, which provides evidence that the proportional hazard assumption was met. 
In order to test for the robustness of our analysis we need to account for unobserved heterogeneity. Unobserved heterogeneity consists of factors not explicitly included in the model, which are correlated with those included in the model that might bias the estimated effects. While we cannot observe all firm-specific heterogeneity, we could model it assuming the presence of firm-specific random-effects, which are assumed to be distributed according to an inverse Gaussian distribution for computational convenience (Han and Hausman, 1990; Hougaard, 1984; Manton, Stallard and Vaupel, 1986), which we discuss later. We discuss the results in the next section.

\section{Results}

Hypothesis 1 states that the survival time of new firms has a curvilinear (taking an inverted U-shape) relationship to the degree of business model innovation, wherein new firms with a high or low degree of business model innovation are more likely to survive for longer than new firms with a moderate degree of business model innovation. Table 5 examines the association between survival of the new firms and the degree of business model innovation. We include both a measure of degree of business model innovation and degree of innovation squared. Model 1 includes the main explanatory variable and the control variables. Model 2 includes the interaction term for the degree of business model innovation and the third-party alliance formed. Models 3 and 4 include the inverse Gaussian distribution to capture any unobserved heterogeneity for Models 1 and 2 respectively.

When the coefficient of the hazard model is larger than 1, it implies that, as the covariate increases, so does the hazard rate (i.e., the time of exit of the firms is advanced). On the other hand, when the coefficient of the hazard model is less than 1 , as the covariate increases, the hazard rate decreases (i.e., the time of exit of the firms is delayed). 
The coefficient for the direct relationship between the degree of business model innovation and the hazard rate is significant and larger than 1, showing that the degree of business model innovation is an important factor in explaining the survival of the firms. However, the significant coefficient of less than 1 for the degree of business model innovation squared in all models implies that as the degree of business model innovation increases, the time of exit by firms is advanced initially and then delayed. In other words, the survival time for firms is higher when the degree of business model innovation is low or high, but when the degree of business model innovation is moderate the survival time is the shortest. This result provides support for Hypothesis 1. Our model is robust to a different distribution. In order to check for robustness we also ran the model with a Weibull distribution and we obtained similar results to those of Model 1. Among the control variables we find entrepreneur as owner-manager, breadth of products and geographical coverage to be consistently significant.

\section{Table 5 about here.}

Hypothesis 2 states that the relationship between a new firm's degree of business model innovation and survival is negatively moderated by partnering with third-party firms with complementary assets. In order to test Hypothesis 2, we ran the model with the interaction term between the degree of business model innovation and third-party alliance variable. This is shown in Model 2 of Table 5. The coefficient for the direct relationship between the thirdparty alliance and the hazard rate is significant and smaller than 1 , showing that the thirdparty alliance is an important factor in enhancing the survival of the firms. The significant coefficient of more than 1 for the interaction between the degree of business model innovation and third-party alliance implies that third-party alliance reduces the effect of survival of the new firms as the degree of business model innovation increases. This result provides support for Hypothesis 2. 
In order to understand better how the moderated effect (third-party alliance) reflects the hypothesized relationship, we conduct effect size interpretation of the interaction term (Carr, Boyar and Gregory, 2008; Trevor, 2001). Using the unstandardized coefficient of the model with the moderated term, the total effect on the hazard rate multiplier and the change in survival likelihood of the firms for high and low levels (the presence or absence) of thirdparty alliance on the degree of business model innovation were calculated to test Hypothesis 2. The first step in interpreting the impact on firm survival likelihood is to examine the moderating variable: third-party alliance at low and high values (for instance, +1 and -1 to account for a one standard deviation increase or decrease in the variable of interest). The hazard ratios for the degree of business model innovation and the interaction term of degree of business model innovation and third-party alliance are 1.97 and 1.58 respectively based on Model 4 (Model 4 includes a Gaussian distribution to account for unobserved heterogeneity which we discuss later). This gives corresponding non-exponentiated values of 0.68 and 0.48 respectively. Consequently, a one standard-deviation increase in the degree of business model innovation results in a 3.1 multiplier of the hazard rate (that is, $\exp [0.68+0.48]$ ), and subsequently a 211 per cent decrease in survival rate for the new firm at any time $t$, when third-party alliance is high (presence). The same increase in the degree of business model innovation translates to a 1.2 multiplier and a 24.7 decrease in survival rate for the new firms at any time $t$, when third-party alliance is low (absence). Thus, when third-party alliance is high, the effect of the degree of business model innovation on the survival rate of new firms decreases by almost 10 times compared to when third-party alliance is low, providing support for Hypothesis 2.

Our model is robust to a different distribution. In order to check for robustness we also ran the model with a Weibull distribution and obtained similar results to those of Model 2. 
Among the control variables we find entrepreneur as owner-manager, breadth of products, geographical coverage and size to be consistently significant.

In addition, we ran the model to account for unobserved heterogeneity by using the inverse Gaussian distribution. The theta that captures the unobserved heterogeneity is not significant, which implies that unobserved heterogeneity is not an issue for our model, as shown in Models 3 and 4 respectively. The results of Model 3 are consistent with those of Model 1. Hence, Hypothesis 1 is supported. The results of Model 4 are consistent with those of Model 2. Hence, Hypothesis 2 is supported.

One possible issue for the phenomenon we are addressing is that firms partnering other third-party firms for complementary assets are tailoring their degree of business model innovation accordingly. However, we eliminate such possibilities because correlation between third-party alliance and the degree of business model innovation is negative and not significant, as shown in Table 4.

Impact of profits: In order to further illuminate the results of our study, we examine the relationship between the degree of business model innovation and profit. Since our sample consists of new firms, the performance in terms of profits or market share is not reported publicly and hence not available. Therefore, we proxy the performance of these new firms by constructing two variables. The first examines the number of times from the initial launch that the firm diversified and launched a separate product (financial instrument in this case) that was different from the initial product (obtained from BMI reports and press releases). Arguably, the more times a firm launches new products in the initial years that are distinct from its stated strategy, the less successful it will be in capturing sufficient market share from its initial product category. The second proxy for performance examines the number of times the new firm raised external finance following its launch as a result of a shortage of cash 
(obtained from BMI reports and press releases). Arguably, the more times a firm raises external funding, the less successful it is in generating cash internally from the operations of its existing business. We analyzed the degree of business model innovation against these two measures of performance and report the results in Table 6 (which reports the average for these two proxy profit measures for different degrees of business model innovation). The analysis in Table 6 shows that performance is best when the degree of business model innovation is low (scales 1-2) and when it is high (scales 4-5), and worst when the degree of business model innovation is moderate (scale 3). This result is consistent for both proxy measures of profit, as shown in Table 6. We conducted a paired $t$-test, which shows that the proxy performance measures are different across the degree of business model innovation $(\mathrm{p}<.01)$. Therefore, the performance of the business model appears to follow the same pattern as the survival of the firms, whereby high performance is associated with an increased survival rate, and this is so when the degree of business model innovation is either low or high.

Table 6 about here.

Interviews with firms: In order to further explore our results we conducted interviews with 35 managers from the electronic trading platform firms. Our interviews reveal support for our empirical findings. A senior executive in one of the firms articulated the importance of the degree of business model innovation on survival:

Often the best approach to create superior performance in the electronic bond trading market is either to innovate the business model incrementally so users can get used to the change slowly or alternatively to go for a radical business model innovation as this enables the game to be changed dramatically which leaves competitors behind.

Another executive went on to articulate the importance of third-party alliance: 
We find that often partnering other firms helps. However, the partnering approach is most effective when the business model is not altered radically as it creates significant complexity and coordination costs.

\section{Discussion and Implications}

In summary, we find a highly significant U-shaped relationship between the degree of business model innovation and the survival time of the new firms. Moreover, we show that partnering with third-party firms with complementary assets reduces the survival of new firms as the degree of business model innovation increases.

We believe that our study makes several important contributions. First, we establish the contingent role of the degree of business model innovation on firm survival. Second, we explore the fit between a focal firm's degree of business model innovation and third-party alliance for complementary assets on survival. In doing so, we explore the notion that the business model construct transcends the boundary of the firm to effect transactions. These two contributions highlight the degree of business model innovation as a source of competitive advantage and provide an initial step towards understanding better the associated contingent structural factors that might influence firm performance.

Our study shows that the profit (as per the proxy measures) of the business model appears to follow the same pattern as the survival of the firms, whereby high performance is associated with either a low or high degree of business model innovation, while low performance is associated with a moderate degree of business model innovation. The industry we examine displays strong demand-side externalities, whereby trades would migrate to platforms that have the most market share (or liquidity). This is because buyers/sellers want to trade where other buyers/sellers are trading as it provides them with more information about price levels. Increasingly many Internet-related industries display such network effects 
and, hence, we believe that the pattern we observe between the degree of business model innovation and survival might hold in such markets. Our results need to be empirically tested in industries that do not display strong network effects in order to examine how and when they might be relevant.

The distinction between incremental and radical innovation has been made in the literature based on the degree of newness relative to an existing proposition. The degree of newness can be seen from an internal, as well as external, perspective (Garcia and Calantone, 2002). An internal perspective concerns the firm in terms of technology and other resources and routines. An external perspective concerns the customers and market. In connecting the internal and external perspectives, a number of scholars have made a distinction between innovation that challenges the technical capabilities of the firm and innovation that challenges the firm's knowledge of the market and customer needs (Abernathy and Clark, 1985; Henderson and Clark, 1990). This is a helpful distinction that explains why even a seemingly minor improvement in technological products often results in incumbent firms being unable to respond, which in turn affects their performance adversely. The explanation draws on the notion that distinguishes between the components of the product and the way (Henderson and Clark, 1990) in which they are integrated into the system that is the product architecture. Hence, established firms find it difficult to respond to innovations that change the architecture of the product without changing the components. This is because such architectural knowledge becomes embedded in existing structures and procedures, making it hard to recognize and correct. However, the extant literature examines the issue from a product or process innovation perspective.

Business models can be seen as the organizational design that connects the internal perspective of the firm to the external perspective and therefore captures how the firm goes to market to implement the strategy. Hence, the degree of business model innovation captures 
the newness in the method of doing business that connects the factor market with the customer market. Therefore, business model innovation is more systemic in nature compared to product or process innovation as it concerns the alignment of the customer value proposition with how value is created and captured (Velu and Stiles, 2013). Therefore, it is possible that an incremental product or process innovation results in a radical business model innovation in order to deliver the proposition to market. Moreover, scholars have argued that business model innovation does not necessarily need a new technology; however, new technologies can often act as a catalyst for business model innovation (Baden-Fuller and Haefliger, 2013). In addition, business models typically span an even wider range of firm functions and external partners to access complementary assets than do traditional product or process innovations. Therefore, the coordination challenges and the outcome resulting from change for business model innovation are often less predictable than product or process innovations because of complex feedback loops.

Our findings have several implications for managers, theory and policy-makers. For managers, it appears that the degree of business model innovation is crucial for survival of the venture. Our results suggest that new firms should either follow a cautious approach in trying to innovate their business model or be very radical in their business model innovation in order to ensure long-term survival. A moderate level of business model innovation is the least favourable in terms of ensuring the survival of the new firm. The first approach of incremental business model innovation ensures that the firm is able to gradually learn about the changes in the value proposition, value creation and capture in designing a business model that ensures better performance in terms of survival times. On the other hand, a radical business model innovation ensures that the value proposition is changed drastically, and being a pioneer ensures better performance in terms of survival times. A moderate change, however, has similarities to the 'stuck-in-the-middle' hypothesis of Porter regarding 
corporate strategy, and hence results in a poorer performance in terms of survival times. The findings suggest that managers need to adopt either an incremental or a radical business model innovation to accommodate any degree of product or process innovation rather than adopting a moderate business model innovation in order to ensure superior performance and ultimately survival. Our second finding suggests that managers should try to avoid overpartnering to leverage complementary assets in the case of radical business model innovation. This is particularly so when the business model innovation accommodates a product or process innovation that might call for partnering. Managers need to understand the potential differential effects of partnering for product and process innovations compared to business model innovation.

This study has implications for theory. Our results have implications for further understanding the relationship between product and process innovation and the role of technology management in influencing the degree of business model innovation. Unpacking this relationship further from a theoretical perspective is required in order to understand the implications on firm performance. On a related matter, our study has implications for further developing the theory on how partnering to access complementary assets for product and process innovations interfaces with business model innovation.

For policy-makers interested in promoting new firm development and innovation in the financial services industry, it is important to provide support for radical business model innovation as well as learning opportunities in order for new firms to test the water using incremental business model innovations. Moreover, policy-makers need to encourage and provide support for alliance formation, especially in the case of firms with incrementally new business models. Arguably, policy-makers would need to take this into account in the financial services industry with the many regulatory changes following the 2008 credit crisis. 


\section{Conclusions}

In this study, we address the question of how the degree of business model innovation affects the survival of new firms. We assembled a new data set of 129 electronic trading platforms in the US bond markets between 1995 and 2004. We find a robust relationship showing that new firms adopting both incremental and radical business model innovations are more likely to survive longer than those adopting moderate business model innovations. We also show that partnering with third-party firms with complementary assets reduces the survival of new firms as the degree of business model innovation increases.

There are certain limitations to our study. First, we have restricted our covariates to be non-time varying, which could affect the effect of business model innovation on the survival of new firms. Second, we do not study how the business models of the new firms evolve over time and how this affects survival. We leave these issues to be examined in future studies, but we hope that the current study provides a starting-point for further investigation into how the degree of business model innovation affects the survival of new firms.

Acknowledgments: I would like to thank Arun Jacob and Shareen Kaur for help with the data collection and analysis. The author thanks Sriya Iyer for comments on earlier versions of this article. 
Table 1: Difference between incremental and radical business model innovations

\begin{tabular}{|c|c|c|}
\hline $\begin{array}{l}\text { Business Model } \\
\text { Components }\end{array}$ & $\begin{array}{l}\text { MarketAxess - An } \\
\text { Example of an Incremental } \\
\text { Business Model Innovation }\end{array}$ & $\begin{array}{l}\text { BondBook - An Example of } \\
\text { a Radical Business Model } \\
\text { Innovation }\end{array}$ \\
\hline \multirow[t]{3}{*}{$\begin{array}{l}\text { Value proposition and value } \\
\text { creation }\end{array}$} & $\begin{array}{l}\text { Marginal changes to the } \\
\text { product (from telephone to e- } \\
\text { trading platform). }\end{array}$ & $\begin{array}{l}\text { Significant changes to the } \\
\text { product (from telephone to e- } \\
\text { trading directly between } \\
\text { investors). }\end{array}$ \\
\hline & $\begin{array}{l}\text { Marginal changes to the } \\
\text { distribution (buyers and } \\
\text { sellers still trade through a } \\
\text { dealer bank acting as an } \\
\text { intermediary, except that it } \\
\text { occurs over the electronic } \\
\text { platform rather than via } \\
\text { telephone). }\end{array}$ & $\begin{array}{l}\text { Significant changes to the } \\
\text { distribution (from dealers } \\
\text { acting as intermediary to } \\
\text { direct trading between buyers } \\
\text { and sellers, which enables a } \\
\text { more transparent, } \\
\text { comprehensive and unfiltered } \\
\text { view of the market place). }\end{array}$ \\
\hline & $\begin{array}{l}\text { Marginal changes to the } \\
\text { promotion (which remains } \\
\text { active and dealer-led, but } \\
\text { occurs over the electronic } \\
\text { platform rather than via } \\
\text { telephone). }\end{array}$ & $\begin{array}{l}\text { Significant changes to } \\
\text { promotion (from being } \\
\text { actively dealer-led to being } \\
\text { passively buyer-initiated } \\
\text { information-gathering on the } \\
\text { e-platform). }\end{array}$ \\
\hline Value capture & $\begin{array}{l}\text { Enabled via the difference } \\
\text { between buy and sell prices } \\
\text { for the securities (bonds). }\end{array}$ & $\begin{array}{l}\text { Enabled via transaction fees } \\
\text { or credit guarantee fees for } \\
\text { each transaction. }\end{array}$ \\
\hline
\end{tabular}


Table 2: Summary of the measures and the relevant data sources

\begin{tabular}{lll} 
Conceptual Variable & Measure & Data Source \\
\hline Business model innovation & The degree of business & Survey among experts \\
& model innovation & \\
\hline Third-party alliance & Whether there was an & BMA reports \\
& alliance with a third party & \\
\hline Entrepreneurs as O-M & Entrepreneurs involved as & Press release \\
& owner-managers & \\
\hline Competition & Average relative number & BMA reports \\
& of firms in each segment & \\
\hline Breadth & Number of instruments & BMA reports \\
& traded & \\
\hline Geographic spread & Dummy indicating US \& & BMA reports, press release \\
& Europe presence & \\
\hline Size & Whether incumbent bank & BMA reports, press release \\
& had an equity stake & \\
\hline
\end{tabular}


Table 3: Extract of survey on business model innovation

\section{Traditional Business Model}

The traditional business model for trading bonds involves transactions carried out via the telephone. Customers typically call multiple broker-dealers to get a quote for a buy or sell order. Broker-dealers in turn quote prices for the buy or sell orders. Broker-dealers typically make a market by holding securities in inventory in order to match the supply and demand of the bonds over time. In doing so, broker-dealers could act as a principal for the transaction as they are sometimes able to deliver the bonds from their own inventory. Broker-dealers earn their revenue from the difference between the buy and sell prices.

\section{New Business Model}

LogicTrade is a real-time Internet-based service for trading high-yield and distressed corporate debt, convertible bonds, emerging-markets bonds and municipal securities with full anonymity and price transparency in a highly secure system. Users are able to see buy and sell orders, entered by broker-dealers and institutional investors, as they are entered into the system, as well as price and quantity information for all trades as they occur. The system automatically matches orders on a strict price/time priority basis. In addition, LogicTrade provides free, real-time detailed financial news regarding the issuers whose securities are available for trading. LogicTrade market participants are able to receive quotes on and purchase municipal bond insurance from the Municipal Bond Insurance Association (MBIA Inc.). LogicTrade does not trade for its own account, acts as riskless principal in all transactions and discloses the mark-ups and mark-downs for each transaction. LogicTrade in turn earns a fee for each transaction as its source of revenue.

Note: The name of the new business model, LogicTrade, has been changed to preserve anonymity. 
Table 4: Descriptive statistics and correlation matrix

\begin{tabular}{|c|c|c|c|c|c|c|c|c|c|c|c|}
\hline & & $\mathrm{M}$ & $\mathrm{SD}$ & 1 & 2 & 3 & 4 & 5 & 6 & 7 & 8 \\
\hline 1 & Failure & 0.64 & 0.48 & 1.00 & & & & & & & \\
\hline 2 & $\begin{array}{l}\mathrm{BM} \\
\text { innovation }\end{array}$ & 2.65 & 0.69 & -0.11 & 1.00 & & & & & & \\
\hline 3 & $\begin{array}{l}\text { Third-party } \\
\text { alliance }\end{array}$ & 0.22 & 0.42 & -0.15 & -0.09 & 1.00 & & & & & \\
\hline 4 & $\begin{array}{l}\text { Entrepreneur } \\
\text {-ship }\end{array}$ & 0.27 & 0.44 & $0.28 *$ & 0.09 & $-0.20 *$ & 1.00 & & & & \\
\hline 5 & Competition & 17.58 & 10.84 & $-0.19 *$ & -0.04 & 0.01 & 0.01 & 1.00 & & & \\
\hline 6 & Breadth & 2.13 & 1.51 & $0.24 *$ & 0.10 & 0.03 & 0.08 & -0.05 & 1.00 & & \\
\hline 7 & $\begin{array}{l}\text { Geographic } \\
\text { spread }\end{array}$ & 0.21 & 0.41 & -0.17 & 0.00 & 0.15 & -0.15 & -0.09 & 0.15 & 1.00 & \\
\hline 8 & Size & 0.29 & 0.45 & 0.07 & 0.06 & -0.11 & -0.05 & -0.07 & -0.02 & 0.14 & 1.00 \\
\hline
\end{tabular}


Table 5: Models for duration of new firm survival

\begin{tabular}{|c|c|c|c|c|}
\hline & \multicolumn{4}{|c|}{ Dependent Variable: Survival Time } \\
\hline $\begin{array}{l}\text { Independent } \\
\text { Variables }\end{array}$ & & \multicolumn{3}{|c|}{$\begin{array}{l}\text { Hazard Model (with exponential } \\
\text { distribution) }\end{array}$} \\
\hline Model & M1 & M2 & M3 & M4 \\
\hline $\begin{array}{l}\text { Business model } \\
\text { innovation }\end{array}$ & $\begin{array}{c}3.64 * * * \\
(0.89)\end{array}$ & $\begin{array}{c}2.74 * * * \\
(0.95)\end{array}$ & $\begin{array}{c}3.46^{* * * *} \\
(0.81)\end{array}$ & $\begin{array}{l}1.97 * * \\
(0.66)\end{array}$ \\
\hline $\begin{array}{l}\text { Business model } \\
\text { innovation squared }\end{array}$ & $\begin{array}{c}0.72 * * * \\
(0.01) \\
\end{array}$ & $\begin{array}{c}0.75^{* * * *} \\
(0.03)\end{array}$ & $\begin{array}{c}0.71 \text { *** } \\
(0.02)\end{array}$ & $\begin{array}{c}0.77 * * * * \\
(0.04)\end{array}$ \\
\hline $\begin{array}{l}\text { Third-party } \\
\text { alliance }\end{array}$ & $\begin{array}{c}0.60 * * * \\
(0.05)\end{array}$ & $\begin{array}{c}0.32 * * * \\
(0.01)\end{array}$ & $\begin{array}{l}0.49 * * \\
(0.16)\end{array}$ & $\begin{array}{c}0.15 * * * \\
(0.07)\end{array}$ \\
\hline Entrepreneurship & $\begin{array}{c}3.07 * * * \\
(0.15)\end{array}$ & $\begin{array}{c}3.04 * * * \\
(0.17)\end{array}$ & $\begin{array}{c}3.75^{* * * *} \\
(1.10)\end{array}$ & $\begin{array}{c}3.94 * * * \\
(1.36)\end{array}$ \\
\hline Competition & $\begin{array}{c}0.98 \\
(0.01) \\
\end{array}$ & $\begin{array}{c}0.98 \\
(0.14) \\
\end{array}$ & $\begin{array}{c}0.98 \\
(0.02) \\
\end{array}$ & $\begin{array}{c}0.98 \\
(0.02) \\
\end{array}$ \\
\hline Breadth & $\begin{array}{c}1.19 * * * \\
(0.03)\end{array}$ & $\begin{array}{l}1.19 * * \\
(0.03)\end{array}$ & $\begin{array}{c}1.26 * * * \\
(0.02)\end{array}$ & $\begin{array}{c}1.27 * * * \\
(0.02)\end{array}$ \\
\hline Geographic spread & $\begin{array}{c}0.36^{* * * *} \\
(0.03)\end{array}$ & $\begin{array}{c}0.36^{* * * *} \\
(0.03)\end{array}$ & $\begin{array}{c}0.29 * * * \\
(0.05)\end{array}$ & $\begin{array}{c}0.27 * * * \\
(0.06)\end{array}$ \\
\hline Size & $\begin{array}{c}1.68 \\
(0.42) \\
\end{array}$ & $\begin{array}{l}1.72 * * \\
(0.41)\end{array}$ & $\begin{array}{c}1.88 \\
(1.02) \\
\end{array}$ & $\begin{array}{c}2.05 \\
(1.22) \\
\end{array}$ \\
\hline $\begin{array}{l}\text { Business Model } \\
\text { Innovation*Third- } \\
\text { party alliance }\end{array}$ & & $1.29 * * *$ & & $\begin{array}{c}1.58 * * * \\
(0.04)\end{array}$ \\
\hline $\begin{array}{l}\text { Variance of } \\
\text { heterogeneity } \\
\text { distribution }\end{array}$ & & & 0.20 & 0.27 \\
\hline $\begin{array}{l}\text { Log } \\
\text { pseudolikelihood }\end{array}$ & $-61.07 * * *$ & $-60.93 * * *$ & $-60.70 * * *$ & $-60.38 * * *$ \\
\hline $\mathrm{N}=129$ & & & & \\
\hline
\end{tabular}

Note:

(1) Standard errors given inside parentheses.

(2) The significance of the Log pseudolikelihood at the 1 per cent level shows that at least one of the regression coefficients in the model is not equal to 0 (Green and Hensher 2010, pp. 153-4).

(3) The heterogeneity distribution is an Inverse Gaussian distribution. 
Table 6: Degree of business model innovation and performance

\begin{tabular}{|l|c|c|c|}
\hline & \multicolumn{3}{|c|}{ Degree of Business Model Innovation } \\
\hline & Low (Scales 1-2) & Moderate (Scale 3) & High (Scale 4-5) \\
\hline $\begin{array}{l}\text { The average number } \\
\text { of times from initial } \\
\text { launch that the firm } \\
\text { has diversified and } \\
\text { launched a separate } \\
\text { product }\end{array}$ & 1.51 & 2.02 & 1.31 \\
\hline $\begin{array}{l}\text { The average number } \\
\text { of times the new firm } \\
\text { raised external } \\
\text { finance following its } \\
\text { launch as result of a } \\
\text { shortage of cash }\end{array}$ & 1.28 & & 1.38 \\
\hline
\end{tabular}




\section{References}

Abernathy, W.J., Clark, K.B. 1985. Innovation: mapping the winds of creative destruction. Research Policy, 14, 3-22.

Aghion, P., Bloom, N.R., Blundell, R., Griffith. R., Howitt, P., 2005. Competition and innovation: An inverted U-relationship. The Quarterly Journal of Economics, May, 701-28.

Aspara, J., Lamberg, J-A., Laukia, A and Tikkaen, H. 2013. Corporate Business Model Transformation and Inter-Organizational Cognition: The Case of Nokia. Long-Range Planning 46(6), 459-474.

Baden-Fuller. C., Morgan, M.S., 2010. Business models as models. Long-Range Planning 43(2-3), 156-171.

Baden-Fuller. C., Haefliger, S., 2013. Business models and technological innovations. LongRange Planning 46(6), 419-426.

Bock, A.J., Opsahl, T., George, G., Gann, D.M., 2012. The effects of culture and structure on strategic flexibility during business model innovation. Journal of Management Studies, 49(2), 279-305.

Buddelmeyer, H., Jensen, P.H., Webster, E., 2010. Innovation and the determinants of company survival. Oxford Economic Papers 62 (2), 261-285.

Calia, R.C., Guerrini, F.B., Moura, G.L., 2007. Innovation networks: From technological development to business model reconfiguration. Technovation 27(8), 426-432.

Carr, J.C., Boyar, S.L., Gregory, B.T., 2007. The moderating effect of work-family centrality on work-family conflict, organizational attitudes and turnover behaviour? Journal of Management, 34, 244-262.

Chandy, R., Tellis, G., 1998. Organizing for radical product innovation: The overlooked role of the willingness to cannibalize. Journal of Marketing Research 35, 474-487.

Chen, S-H., Wen, P-C., Yang, C-K., 2014. Business concepts of systemic service innovations in e-healthcare. Technovation, 34(9), 513-524. 
Christensen, C.M., 1997. The Innovator's Dilemma: When New Technologies Cause Great Firms to Fail. Harvard Business School Press, Boston.

Chung, W., Kalnins, A., 2001. Agglomeration effects and performance: a test of the Texas lodging industry. Strategic Management Journal, 22, 969-988.

Cohen, W.M., Klepper, S., 1996. Firm size and the nature of innovation within industries: the case of process and product R\&D. Review of Economics and Statistics 78 (2), 232-243.

Colombo, M and M, Delmastro, (2001). Technology use and plant closure. Research Policy, 30(1), 21-34.

Daneels, E., 2004. Disruptive technology reconsidered: A critique and research agenda, Journal of Product Innovation Management 21, 246-258.

Dasgupta, P., 2002. Modern Economics and its Critiques. In: Maki, U. (Ed.), Fact and Fiction in Economics: Models, Realism and Social Construction. CUP, Cambridge.

Debreu, G., 1991. The Mathematization of economic theory. American Economic Review 81 (March), 1-7.

De Luca, L.M., Atuahene-Gima, K., (2007). Market knowledge dimensions and crossfunctional collaboration: examining the different routes to product innovation performance. Journal of Marketing, 71, 95-112.

Demil, B., Lecocq, X., 2010. Business model evolution: In search of dynamic consistency. Long Range Planning 43 (2-3), 227-246.

Dess, G., Robinson, R., 1984. Measuring organizational performance in the absence of objective measures: The case of the privately held firm and conglomerate business unit. Strategic Management Journal 5(3), 265-273.

Desyllas, P., Sako, M., 2013. Profiting from business model innovation: evidence from PayAs-You-Drive auto industry, Research Policy, 42 (2013), pp. 101-116. 
Denicolai, S., Ramirez, M. and Tidd, J. 2014. Creating and capturing value from external knowledge: the moderating role of knowledge intensity. R\&D Management, 44(3), 248-264. Doz, Y.L., Kosonen, M., 2010. Embedding strategic agility: A leadership agenda for accelerating business model renewal, Long Range Planning 43(2-3), 370-382.

Dunne, T., Roberts, M.J., Samuelson, L., 1989. The growth and failure of U.S. manufacturing plants. The Quarterly Journal of Economics 104 (4), 671-698.

Esslinger, H., 2011. Sustainable design: Beyond the innovation driven business model. Journal of Product Innovation Management 28, 401-404.

Fiet, J.O., Patel, P., 2008. Forgiving business models for new ventures. Entrepreneurship Theory and Practice, 32(4): 749-761.

Friedman, R.S., Roberts, D.M. and Linton, J.D. Technology and Innovation Management: Foundational and Fundamental Knowledge. Hershey, PA: Idea Group Inc. (IGI), 2008.

Garcia, R., Calantone, R., 2002. A critical look at technological innovation typology and innovativeness terminology: a literature review. Journal of Product Innovation Management 19: $110-132$.

GE Global Innovation Barometer, 2013. Global Research and Findings and Insights, General Electric Corporation, New York.

George, G., Bock, A.J., 2011. The business model in practice and its implications for entrepreneurship research. Entrepreneurship Theory and Practice 35, 83-111.

Han, A., Hausman, J.A., 1990. Flexible parametric estimation of duration and competing risk models. Journal of Applied Econometrics 5(1), 1-28.

Henderson, R., Clark, K.B., 1990. Architectural innovation: the reconfiguration of existing product technologies and the failure of established firms. Administrative Science Quarterly 35, 9-30. 
Hosmer, D.H., Lemeshow, S., 1999. Applied survival analysis: Regression modeling of time to event data. New York: Wiley \& Sons.

Hougaard, P., 1984. Life table methods for heterogeneous populations: Distributions describing the heterogeneity. Biometrika 71(1), 75-83.

IBM, 2008. Global CEO Study: The Enterprise of the Future (IBM Global Business Services).

Johnson, W., Christensen, C., Kagermann, H., 2008. Reinventing your business model. Harvard Business Review 86 (12), 50-59.

Klepper, S. 1996. Entry, exit, growth, and innovation over the product life cycle. American Economic Review, 86, 562-583.

Landy, R., Amara, N., Cloutier, J-S, Halilem, N. 2013. Technology transfer organizations: Service and business models. Technovation, 33(12), 431-449

Langerak, F., Rijsdijk, S., Dittrich, K., 2009. Development time and new product sales: A contingency analysis of product innovativeness and price. Marketing Letters 20, 399-413. Linton, J.D., 2009. De-Babelizing the Language of Innovation. Technovation, 29(11): 729737.

Manton, K.G., Stallard, E., Vaupel, J.W., 1986. Alternative models for the heterogeneity of mortality risks among the aged. Journal of the American Statistical Association 81, 635-644. Markides, C., 2006. Disruptive Innovation: In Need of Better Theory. Journal of Product Innovation Management 23, 19-25.

Min, S., Kalwani, M.U., Robinson, W.T., 2006. Market pioneer and early follower survival risks: A contingency analysis of really new versus incrementally new product-markets. Journal of Marketing 70 (January), 15-33.

Nunnally, J.C., 1978. Psychometric Theory. McGraw-Hill Publishing Company, New York. 
Patzelt, H., Knyphausen-Auseb, D., Nikol, P., 2008. Top Management Teams, Business Models, and Performance of Biotechnology Ventures: An Upper Echelon Perspective. British Journal of Management 19, 205-221.

Piggot, C., 2001. Espeed and Tradeweb win the Poll. The Banker 151 (906).

Rust, R., Cooil. B., 1994. Reliability measures for qualitative data: Theory and implications. Journal of Marketing Research 31, 1-14.

Schmidt, K. 1997. Managerial incentives and product market competition. Review of Economic Studies, 64, 191-213.

Sinha, R.K., Noble, C. H., 2008. The adoption of radical manufacturing technologies and firm survival. Strategy Management Journal, 29, 943-962.

Sosna, M., Trevinyo-Rodriguez, R.N., Velamuri, S.M., 2010. Business model innovation through trial and error learning. Long Range Planning 43(2-3), 383-407.

Srinivasan, R., Lilian, G., Rangaswamy, A., 2004. First in, First out? The Effects of Network Externalities on Pioneer Survival. Journal of Marketing 68 (1), 41-58.

Teece, D., 1986. Profiting from technological innovation: implications for integration, collaboration, licensing and public policy. Research Policy 15, 285-306.

Teece, D.J., 2006. Reflections on “Profiting from Innovation”. Research Policy 35, 11311146.

Teece, D., 2010. Business models, business strategy and innovation. Long-Range Planning, $43(2-3), 172-94$.

Tongur, S., Engwall, M. 2014. The business model dilemma of technology shifts. Technovation, 34(9), 525-535.

Trevor, C., 2001. Interactions among ease-of-movement determinants and job satisfaction in the prediction of voluntary turnover, Academy of Management Journal, 44(4), 621-638. 
Utterback, J.M., 1994. Mastering the Dynamics of Innovation: How Companies Can Seize Opportunities in the Face of Technological Change. Harvard University Press, Boston. Velu, C., Stiles, P., 2013. Managing Decision-Making and Cannibalization for Parallel Business Models. Long Range Planning, 46, 443-458.

Vidal, E., Mitchell, W., 2013. When Do First Entrants Become First Survivors? Long Range Planning, 46, 335-347.

Zott, C., Amit, R., 2001. Value creation in e-business. Strategic Management Journal, 22: $493-520$.

Zott, C., Amit, R., 2008. The fit between product market strategy and business model: Implications for firm performance. Strategic Management Journal 29, 1-26.

Zott, C., Amit, R., Massa, L., 2011. The Business model: Recent developments and future research. Journal of Management 37, 1019-1042. 